\title{
Dexpanthenol: An Overview of its Contribution to Symptom Relief in Acute Rhinitis Treated with Decongestant Nasal Sprays
}

\author{
Ralph Mösges · Kija Shah-Hosseini · Hans-Peter Hucke · Marie-Josefine Joisten
}

Received: March 16, 2017 / Published online: July 10, 2017

(C) The Author(s) 2017. This article is an open access publication

\begin{abstract}
Nasal blockage is the most bothersome symptom of acute rhinitis. Nasal decongestant sprays containing alpha-sympathomimetics, such as oxymetazoline and xylometazoline, have a rapid onset of action. However, this effect decreases with repeated application and, furthermore, the ciliary function of the nasal mucosa is practically paralyzed. Dexpanthenol promotes cell proliferation and protects the epithelium. Combining these two agents has demonstrated beneficial synergetic effects on the symptoms of acute rhinitis. In a post hoc analysis of a large-scale double-blind, active-controlled study including 152 patients, we could demonstrate that the benefit of added dexpanthenol appears as early as on the third day of the combined application of xylometazoline and dexpanthenol in terms of complete or near-to-complete freedom from symptoms.
\end{abstract}

Enhanced content To view enhanced content for this article go to http://www.medengine.com/Redeem/ 8BD8F0604A02ED5E.

R. Mösges · K. Shah-Hosseini · M.-J. Joisten ( $\varangle)$ Faculty of Medicine, Institute of Medical Statistics, Informatics and Epidemiology, University of Cologne, Cologne, Germany

e-mail: marie-josefine.joisten@uni-koeln.de

H.-P. Hucke

GASD mbH, Neuss, Germany
After 5 days, $47 \%$ of the patients were cured under the combined treatment compared with only $1 \%$ under xylometazoline monotherapy. These data show that the addition of dexpanthenol to an alpha-sympathomimetic nasal spray not only improves its tolerability but also further increases its effectiveness and leads to expedited cure.

Funding: Klosterfrau Healthcare Group.

Keywords: Acute rhinitis; Allergy; Dexpanthenol; Nasal blockage; Nasal decongestant spray; Xylometazoline

\section{INTRODUCTION}

The nose serves several functions, such as the warming, moistening, and cleaning of inspired air. The nose guides the air to the olfactory cleft, which is essential for the sense of odor, a mandatory prerequisite for quality of life [1]. Physiologically, inspiration functions via nasal breathing and mouth breathing, whereas the latter lacks the advantages of clean, warm, humid nasally inspired air [2]. The respiratory mucosal tissue contains different sorts of glands which produce the protective nasal secretory mucus. Vagal stimulation, parasympathomimetics, and nasally active peptides can increase nasal secretion from tubuloalveolar glands. Alpha- and beta-adrenergic substances 
may also increase this secretion, as well as unspecific local irritation.

Acute rhinitis is mostly caused by viral infection without viremia, without fever, and with preponderance of local symptoms but without generalized symptoms. The last of these differentiates it from influenza, which has an incidence clearly lower than the more or less $100 \%$ of the general population suffering from common cold at some time during the winter season. This is a self-limited disease with a mean duration of about 7 days. This viral infection causes an edema of the mucosal membranes with acute inflammatory infiltration of multiple inflammatory cells, namely neutrophils, phagocytes, and lymphocytes. The accompanying vasodilation is mostly caused by defense mechanisms rather than by viral invasion causing cell defects. The unspecific defense includes the kinin system, interferon, and natural killer cells accompanied by activation of complement. Hyperemia and hypersecretion may lead to local pain mediated by trigeminal nociceptors in the mucosal tissues. The defense mechanisms also result in nasal blockage, hypersecretion, local itching and pain with sneezing as a consequence, and an increase in circulating mast cells. Histamine may also play a role during the acute infectious phase.

The virus infection also induces defects in the muscle tissue and thereby reduces mucociliary transportation which is one of the major defense mechanisms against the adherence of bacteria. Consequently, this can lead to bacterial superinfection mainly of the paranasal sinuses.

Apart from the rhinitis symptoms of itching, pain, and pruritus, certain typical signs of the disease can be assessed by the well-established method of rhinoscopy with or without the use of an endoscope by a skilled otorhinolaryngologist. These signs are mainly redness and hyperplasia of the mucosal tissue and hypersecretion. In the region of the turbinates, the nasal septum, and the ostia of the paranasal sinuses, bulging tissue containing venous sinusoids can be found, surrounded by smooth muscles. Alpha-adrenergic stimulation determines the mucosal thickness of this part of the nasal tissue $[3,4]$. Neurogenic inflammation caused by the release of the neurotransmitter substance $\mathrm{P}$ may lead to dilatation of nasal vessels (nasal obstruction) and an increase in the permeability of nasal vessels (hypersecretion).

The purpose of this post hoc analysis was to compare the proportion of patients that can be considered as "cured" under the treatment of xylometazoline alone with those receiving a treatment combined with dexpanthenol. This article does not contain any new studies with human or animal subjects performed by any of the authors.

\section{NASAL DECONGESTANTS IN ACUTE RHINITIS}

\section{Mechanism of Action of Decongestants in Acute Rhinitis}

Topical decongestants may come in the form of nasal sprays or nasal drops containing oxymetazoline and xylometazoline. Nasal decongestants may have systemic bioavailability causing unwanted alpha-adrenergic effects, such as an increase in blood pressure. Their primary effects, however, are local, resulting in the constriction of capillary vessels with a reduction in the thickness of the mucosa, and a decrease in local perfusion. This situation leads to a reduction in hypersecretion and reduced nasal blockage $[5,6]$.

Oxy- and xylometazoline upregulate the action of alpha-adrenergic receptors which induce vasal constriction in the capillaries of the nasal tissues, namely in the turbinates. The local glands are less well perfused and consequently produce less secretion; the thickness of the mucosal tissues lining the nasal cavity is visibly reduced [7].

\section{Dexpanthenol for Topical Treatment of Mucosal Tissues}

Dexpanthenol is the alcoholic analogue of pantothenic acid, and it is oxidized to this substance within the tissues [8]. Dexpanthenol has been reported to be an effective antioxidant medication by several previous studies relating to an ischemia-reperfusion-induced renal injury 
model, a testicular ischemia-reperfusion model, and reduced oxidative stress because of gamma radiation and apoptosis [9-11]. Studies have shown that dexpanthenol spray promotes cell proliferation and protects the epithelium. Hosemann et al. showed in an experimental study on paranasal sinuses that dexpanthenol was effective in accelerating wound healing [12]. In another study, Klöcker et al. demonstrated that the combination of dexpanthenol with nasal decongestants significantly decreased the toxic effects of these substances with regard to cilia function and cell growth [13].

\section{Studies Using Nasal Decongestants in Acute Rhinitis}

Deckx et al. reported on four studies using topical nasal decongestants vs. placebo [5], although one of these studies was excluded from the analysis because of suspected bias [14]. As the primary outcome parameter for their Cochrane meta-analysis on the effects of decongestants on nasal congestion, Deckx et al. chose the subject symptom scores (self-reported score of congestion/symptom score) [5]. In the study by Eccles, in which repeated doses of nasal decongestant spray were compared with placebo, she found a standardized mean difference (SMD) of 0.59 corresponding to a moderate clinical effect [15]. She found an immediate effect (SMD 0.51) after 10-15 min as reported by Akerlund, who used a single dose of a nasal decongestant spray in comparison to a placebo spray [16]. For the secondary outcome parameter, nasal airway resistance (NAR), Ferguson reported a significant improvement [17], Akerlund ( $1 \mathrm{~h}$ after single dose) found an effect of 0.68 (SMD), and Eccles demonstrated this effect $(\mathrm{SMD}=0.89)$ after repeated nasal application [18] (objective parameter of NAR). The authors of the Cochrane meta-analysis summarized that as a result of the small number of studies that used a topical nasal decongestant, they were unable to draw conclusions on the effectiveness of oral vs. topical decongestants.

Reinecke and Tschaikin investigated the efficacy of oxymetazoline on the duration of acute rhinitis in 247 patients in their prospective, randomized, placebo-controlled, double-blind clinical trial [14]. Duration of rhinitis was defined as the main efficacy criterion, and time to onset of effects was considered a secondary outcome parameter. They found an onset of action $25 \mathrm{~s}$ after applying oxymetazoline compared with $90 \mathrm{~s}$ after applying spray containing saline solution only $(p<0.001)$. On the second day of treatment, the improvement of symptoms in the oxymetazoline group was significantly better than that in the group receiving saline nasal spray; this significant difference persisted until day 8 of treatment. The authors concluded that the active treatment was able to shorten the duration of the common cold by 2 days, thus one-third of the entire duration of the disease [14]. Ninety-five percent of patients in the oxymetazoline group rated the tolerability of treatment as very good or good compared to $94 \%$ in the placebo group.

On the basis of these placebo-controlled trials, the continuous application of a nasal decongestant spray for a period of 7 days in the treatment of the common cold appears to be effective with regard to reducing the signs and symptoms of the disease and to shortening the period of suffering. There are no safety concerns with regard to the short-term (less than 1 week) application of alpha-sympathomimetics in the nose for the treatment of the common cold.

\section{Studies Using Combined Therapy of Dexpanthenol with a Nasal Decongestant Spray}

While the effects of the use of nasal sprays containing decongestants alone mainly focus on the improvement of nasal obstruction, additional effects can be expected from adding a nurturing substance, such as dexpanthenol. These effects have been studied in two double-blind, active-controlled clinical trials comparing the monosubstance xylometazoline with the combination of dexpanthenol and xylometazoline [19], or oxymetazoline and dexpanthenol [20]. Kehrl et al. showed that in patients suffering from acute rhinitis, the combined administration of xylometazoline and dexpanthenol was more effective than 
xylometazoline monotherapy in decreasing rhinorrhea, nasal obstruction, conchal swelling, and hyperemia of the nasal mucosa. The authors speculated that the more pronounced effect of this combination on signs and symptoms of acute rhinitis was due to the protection of the epithelium by dexpanthenol. In their prospective, randomized, and blinded study involving 100 patients in two groups receiving either oxymetazoline $0.05 \%$ with dexpanthanol $5 \%$ (OD) or xylometazoline $0.1 \%$ (XO) nasal drops, Jagade et al. found more pronounced relief from nasal congestion in the group receiving the combination treatment [20]. This difference reached statistical significance. Also, sneezing and nasal discharge were more significantly reduced in the combination group than in the decongestant-alone group. The same superiority was found for nasal irritation, and the recovery time was significantly reduced by about $40 \%$, which appears to be a clinically relevant reduction. Comparing a liposomal nasal spray with an ointment containing dexpanthenol but no decongestant and with an isotonic sodium chloride spray in rhinitis sicca patients, Hahn et al. found that, concerning the nasal moisturization, the liposomal spray was evaluated better than dexpanthenol and the isotonic spray [21]. We reckon that the efficacy and tolerability of a liposomal spray is good compared to generally recognized treatments of rhinitis sicca with nasal ointments containing dexpanthenol alone and with isotonic nasal sprays.

\section{A post hoc responder analysis of the study by Kehrl}

The onset and the extent of improvement were further assessed by Kehrl et al. in a post hoc analysis of a large-scale double-blind, active-controlled study including 152 patients [19]. This study design is sufficiently powered to allow for conclusions at the evidence level of Ib. At first glance, using xylometazoline as control in this study may appear to be a disadvantage, yet it must be conceded that it is impossible to use a true nasal spray placebo and that substituting it with a saline spray solution, for example, could well improve the disease by almost 30\% [22]. It therefore appears permissible to treat the control group with xylometazoline. An observation period of 5 days is relatively short, considering the disease duration of over 1 week as reported by the authors. Nevertheless, a positive aspect of the study design was the interim observation of all patients after 3 days. It was therefore possible to document an early onset of action based on the objective independent assessment by the investigators without having to refer to the patient diaries.

For the two symptoms of acute rhinitis, namely nasal blockage and rhinorrhea, rated by the patients on a $0-4$ Likert scale $(0=$ absent, 1 = mild, $\quad 2$ = moderate, $\quad 3$ = pronounced, $4=$ very severe), and the two signs of the disease, redness of the nasal mucosa and hyperplasia of the nasal turbinate, assessed using the identical rating scale by the otorhinolaryngologist applying the technique of endoscopic rhinoscopy, thresholds for "cure" were introduced. The combined assessment of subjective and objective symptoms provided a better description of the patients' status. Additionally, the occurrence of "cure" was further determined using the evaluation of "well days". According to Pfaar, a well day is defined as a day when the sum score of four parameters does not exceed 2 and no single parameter is worse than mild [23]. This was also employed in the present study and is outlined in the "Discussion".

In analogy to Klimek et al.'s approach [24], who based their post hoc responder analysis on a VAS score, in our post hoc analysis of the original patient data of the study by Kehrl, a score of 1 or less was defined as cure or clinically significant improvement [19]. Patients had been studied after 3 days and after 5 days of treatment which allowed for an analysis of the course of the disease under the two treatment options, meaning the decongestant alone or in combination with dexpanthenol. After 3 days of treatment, the proportion of cured patients was strikingly different in favor of the group treated with the combination. For the self-assessed symptom of nasal blockage, $80 \%$ of patients under combined treatment were found to be cured compared to $29 \%$ in the decongestant group. This result corresponds well with the objective assessment of turbinate hypertrophy (71\% vs. 29\%). Likewise, the patients' rating of rhinorrhea after 3 days showed that $73 \%$ were 


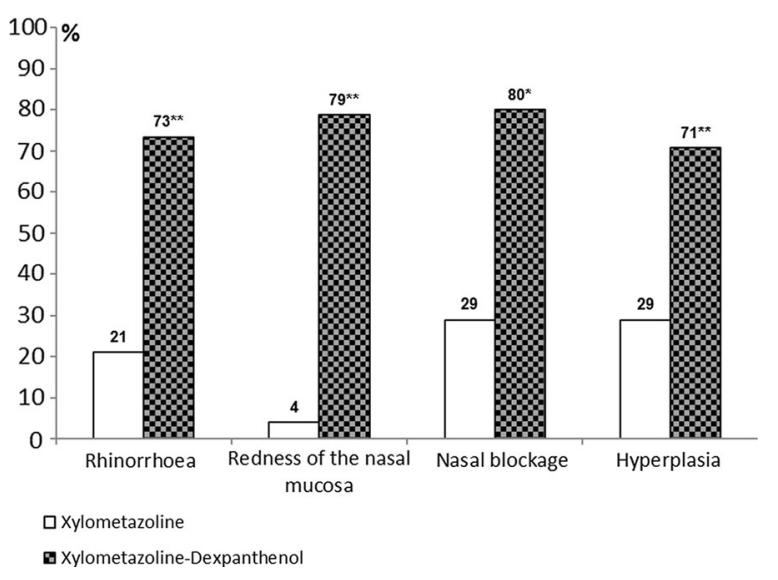

Fig. 1 Proportion of patients with mild or absent signs and symptoms of acute rhinitis (score $\leq 1$ ) after 3 days of treatment for the parameters of rhinorrhea, redness of the nasal mucosa, nasal blockage, and mucosal hypertrophy of the turbinates, comparing xylometazoline monotherapy with the combination of xylometazoline and dexpanthenol. ${ }^{* *} p<0.001$ or ${ }^{*} p<0.01$ compared to xylometazoline

cured under combined treatment compared with $21 \%$ under nasal decongestant spray alone. The objective observation of the redness under endoscopic view confirmed this finding, with a $79 \%$ vs. $4 \%$ ratio of cure (Fig. 1; Table 1). For the overall sum score, cure was defined as a value of 2 or less, with no parameter exceeding a value of 1. Given this definition, $47 \%$ of all patients in the group treated with dexpanthenol in addition to the nasal decongestant can be considered as cured, compared with $1 \%$ in the monotherapy group (Fig. 2; Table 1). All these differences based on a clinically meaningful threshold are statistically significant on the 0.01 level or below. The Chi-squared test was used for the statistical analysis.

\section{DISCUSSION}

Acute rhinitis in the context of a common cold is a disease that has an important health-economic impact. Common colds are frequent illnesses in both children and adults; on average, adults report 2.5 episodes per year. There is a considerable loss of working days, a high number of missed school days, and reduced productivity in patients going to work with

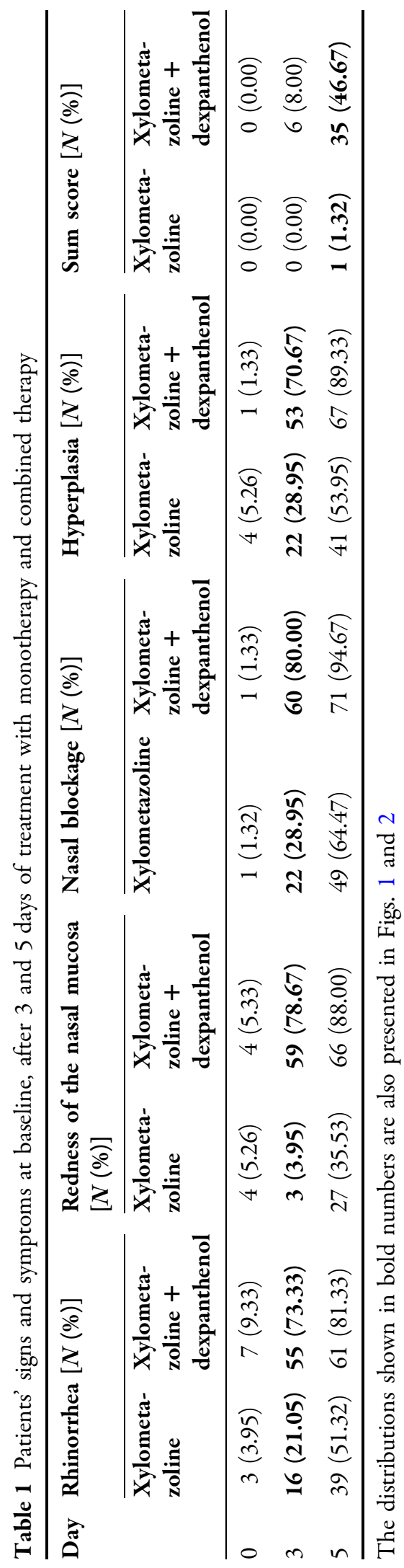




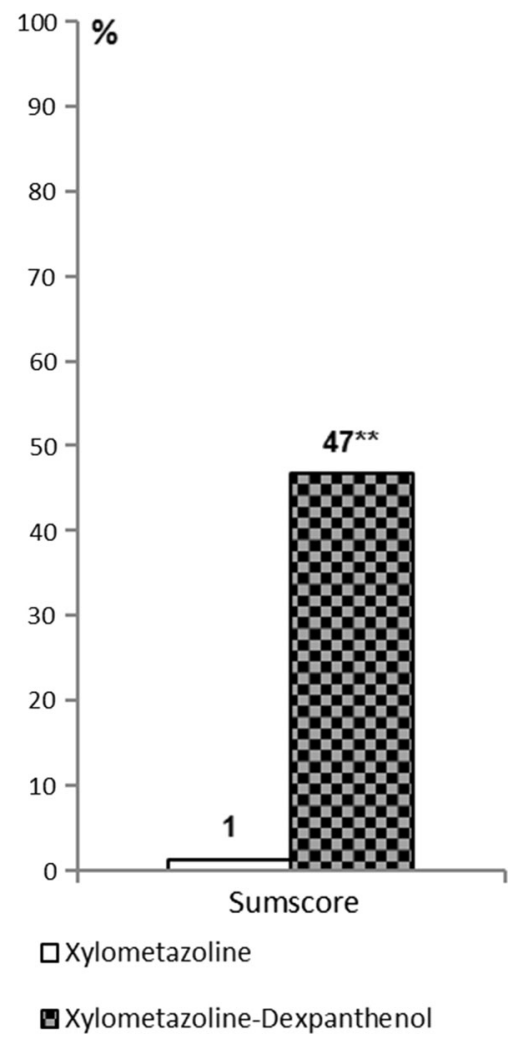

Fig. 2 Proportion of patients cured after 5 days of treatment (sum score $\leq 2$ and individual parameters $\leq 1$ ) comparing xylometazoline monotherapy with the combination of xylometazoline and dexpanthenol. ${ }^{* *} p<0.001$ compared to xylometazoline

symptoms. It has been estimated that the total economic impact of non-influenza-related viral upper respiratory tract infections approaches US $\$ 40$ billion annually [25].

Decongestant nasal sprays have been a matter of debate for decades because of tachyphylaxis under long-term use and the associated risk of addiction. The concept of "privinism" has always been a horror for every otorhinolaryngologist. This issue has been scientifically substantiated in the comprehensive study by Graf $[26,27]$. Opposing evidence is rather an exception, such as that reported by Watanabe in healthy volunteers using oxymetazoline three times daily for 4 weeks [28] and by Yoo for the same duration with treatment administration only in the evenings [29]. Therefore, it is not surprising that alternatives to the alpha-sympathomimetic drugs have been sought for a long time. Our group thoroughly investigated the effects and the tolerability of liposomal nasal sprays and ectoine-containing nasal sprays in several clinical trials [21, 30-35]. We found that both preparations were comparably effective and low in side effects.

Two studies by Passali et al. investigated the effects of a nasal spray containing dexpanthenol for the treatment of allergic rhinitis in children for periods of 4 weeks and 2 weeks, respectively [36, 37]. They studied 100 children in one trial and 50 children in the other trial. In both studies, a significant reduction in all symptoms was observed and mild side effects were reported only in the single-digit percentage range.

Another approach combines xylometazoline with nurturing substances, which has been mentioned by Castellano and Mautone [38] as well as Kehrl and Sonnemann [19]. In 2002, Castellano and Mautone published a double-blind dose-effect clinical trial comparing nasal sprays containing three different concentrations $(0.1 \%, 0.05 \%, 0.025 \%)$ of xylometazoline with or without hyaluronic acid with a control solution that contained benzalkonium chloride as preservative [38]. They found that hyaluronic acid seemingly acts as enhancer/carrier of the active principle of $0.05 \%$ xylometazoline.

Our post hoc analysis of patients who can be considered as "cured" shows that cure is an extreme exception after 5 days of treatment with a nasal decongestant spray, which is still the first-line choice in most guidelines. Ninety-nine percent of patients using the decongestant spray alone still have significant symptoms at this point of their disease. This observation is in line with previous findings published by Mösges et al., who showed that a rhinoscopy score of 2 or less and a self-rated symptom score of 2 or less were only reached after 10 days when patients received only nasal decongestant sprays [39]. In a double-blind, placebo-controlled trial involving 200 patients with viral rhinitis, Eccles et al. found a reduction of symptoms to a mean value of 2 in the group receiving a placebo spray not before day 7 of the disease [40]. The addition of iota-carrageenan, a virostatic agent, did not significantly shorten this period of suffering. In comparison to this, 
the results of our post hoc analysis demonstrate that dexpanthenol at a concentration of 5\% added to the nasal decongestant spray containing xylometazoline can significantly reduce the individual signs and symptoms in a majority of patients as early as 3 days after the start of treatment and thereby reach a cure in almost half of the affected patients within 5 days.

One of the limitations of the trial design is that the study did not have a placebo group. All patients knew that they received at least the treatment recommended by the guidelines $[41,42]$. This knowledge could have added to the effects of the treatment. Two findings, however, are in contrast with this assumption: The results for patients' subjective ratings do not differ considerably from those for the objective observations made by the investigators using endoscopic rhinoscopy. Also, the fact that only 1 out of 76 patients in the xylometazoline group can be considered as cured does not support a strong self-suggestive effect. Given the mechanism of action, it cannot be easily explained why dexpanthenol not only reduces the sign of redness and the symptom of rhinorrhea but also the swelling of the mucosa, leading to a strong reduction of the feeling of nasal blockage in most patients within 3 days. This antiobstructive synergy with a nasal decongestant, which has already been described by Jagade, although not under double-blind, placebo-controlled conditions, needs further clarification [20].

\section{CONCLUSION}

Most guidelines [41, 42] recommend a short treatment course of less than 7 days of nasal decongestant spray as first-line treatment of acute rhinitis. This approach is becoming at least gradually supported by a recent Cochrane analysis. According to the results of our post hoc analysis, the addition of dexpanthenol, a compound with antioxidant and wound-healing properties, appears to have further beneficial effects on the affected nasal mucosa and may reduce the time to cure in acute rhinitis.

\section{ACKNOWLEDGEMENTS}

Sponsorship for this study, article processing charges including the Open Access fees, and editorial assistance was funded by Klosterfrau Healthcare Group. All named authors meet the International Committee of Medical Journal Editors (ICMJE) criteria for authorship of this manuscript, take responsibility for the integrity of the work as a whole, and have given final approval for the version to be published. Editorial assistance was provided by Gena Kittel, B.A..

Disclosures. Ralph Mösges reports personal fees from ALK, allergopharma, Allergy Therapeutics, Friulchem, Hexal, Servier, Klosterfrau, Bayer, FAES, GSK, MSD, Johnson \& Johnson, Meda, Stada, UCB, and Nuvo; grants from ASIT biotech, Leti, BitopAG, Hulka, Optima, and Ursapharm; grants and personal fees from Bencard and Stallergenes; grants, personal fees, and non-financial support from Lofarma; non-financial support from Roxall, Atmos, Bionorica, Otonomy, and Ferrero; personal fees and non-financial support from Novartis, outside the submitted work. Hans-Peter Hucke, Kija Shah-Hosseini, and Marie-Josefine Joisten have nothing to disclose.

Compliance with Ethics Guidelines. This article does not contain any new studies with human or animal subjects performed by any of the authors.

Open Access. This article is distributed under the terms of the Creative Commons Attribution-NonCommercial 4.0 International License (http://creativecommons.org/licenses/ by-nc/4.0/), which permits any noncommercial use, distribution, and reproduction in any medium, provided you give appropriate credit to the original author(s) and the source, provide a link to the Creative Commons license, and indicate if changes were made. 


\section{REFERENCES}

1. Hummel T, Whitcroft $K$, Andrews $P$, et al. Position paper on olfactory dysfunction. Rhinology. 2017. doi:10.4193/Rhin16.248.

2. Klimek L. Entzündliche Erkrankungen der oberen Atemwege. In: Loew D, Rietbrock N, editors. Phytopharmaka III: Forschung und klinische Anwendung. Heidelberg: Steinkopff; 1997. p. 135-50.

3. Riechelmann $\mathrm{H}$, Krekel J, Weihe E, Mann W. Immunhistochemischer Nachweis peptiderger Nervenfasern in der Nasenschleimhaut. In: Fleischer K, Kleinsasser O, editors. Teil II: Sitzungsbericht. Berlin, Heidelberg: Springer Berlin Heidelberg; 1991. p. $157-8$.

4. Eccles R, Bende M, Widdicombe J. Allergic and vasomotor rhinitis pathophysiological aspects: nasal blood vessels. In: Mygind N, PipKorn U, editors. Allergic and vasomotor rhinitis: pathophysiological aspects. Copenhagen: Munksgaard; 1987.

5. Deckx L, De Sutter AI, Guo L, Mir NA, van Driel ML. Nasal decongestants in monotherapy for the common cold. Cochrane Database Syst Rev. 2016;10:CD009612.

6. Taverner D, Latte J. Nasal decongestants for the common cold. Cochrane Database Syst Rev. 2007;1:Cd001953.

7. Dorn M, Hofmann W, Knick E. Tolerance and effectiveness of oxymetazoline and xylometazoline in treatment of acute rhinitis. HNO. 2003;51(10):794-9.

8. Koc ZP, In E, Karslioglu I, Ucer O, Canpolat S. Evaluation of the preventive effect of dexpanthenol in radiation injury by lung perfusion scintigraphy: a preclinical experimental model of radiation injury. Nucl Med Commun. 2015;36(12):1227-32.

9. Altintas R, Parlakpinar H, Beytur A, et al. Protective effect of dexpanthenol on ischemia-reperfusion-induced renal injury in rats. Kidney Blood Press Res. 2012;36(1):220-30.

10. Etensel B, Ozkisacik S, Ozkara E, et al. Dexpanthenol attenuates lipid peroxidation and testicular damage at experimental ischemia and reperfusion injury. Pediatr Surg Int. 2007;23(2):177-81.

11. Slyshenkov VS, Omelyanchik SN, Moiseenok AG, Trebukhina RV, Wojtczak L. Pantothenol protects rats against some deleterious effects of gamma radiation. Free Radic Biol Med. 1998;24(6):894-9.

12. Hosemann W, Gode U, Langer F, Wigand ME. Experimental studies of wound healing in the paranasal sinuses. II. Spontaneous wound healing and drug effects in a standardized wound model. HNO. 1991;39(2):48-54.

13. Klöcker N, Rudolph P, Verse T. Evaluation of protective and therapeutic effects of dexpanthenol on nasal decongestants and preservatives: results of cytotoxic studies in vitro. Am J Rhinol. 2004;18(5):315-20.

14. Reinecke S, Tschaikin M. Investigation of the effect of oxymetazoline on the duration of rhinitis. Results of a placebo-controlled double-blind study in patients with acute rhinitis. MMW Fortschr Med. 2005;147(Suppl 3):113-8.

15. Eccles R, Eriksson M, Garreffa S, Chen SC. The nasal decongestant effect of xylometazoline in the common cold. Am J Rhinol. 2008;22(5):491-6.

16. Akerlund A, Klint T, Olen L, Rundcrantz H. Nasal decongestant effect of oxymetazoline in the common cold: an objective dose-response study in 106 patients. J Laryngol Otol. 1989;103(8):743-6.

17. Ferguson EA, Eccles R. Changes in nasal nitric oxide concentration associated with symptoms of common cold and treatment with a topical nasal decongestant. Acta Otolaryngol. 1997;117(4):614-7.

18. Eccles R. Understanding the symptoms of the common cold and influenza. Lancet Infect Dis. 2005;5(11):718-25.

19. Kehrl W, Sonnemann U, Dethlefsen U. Advance in therapy of acute rhinitis-comparison of efficacy and safety of xylometazoline in combination xylometazoline-dexpanthenol in patients with acute rhinitis. Laryngorhinootologie. 2003;82(4):266-71.

20. Jagade MV, Langade DG, Pophale RR, Prabhu A. Oxymetazoline plus dexpanthenol in nasal congestion. Indian J Otolaryngol Head Neck Surg. 2008;60(4):393-7.

21. Hahn C, Bohm M, Allekotte S, Mosges R. Tolerability and effects on quality of life of liposomal nasal spray treatment compared to nasal ointment containing dexpanthenol or isotonic $\mathrm{NaCl}$ spray in patients with rhinitis sicca. Eur Arch Otorhinolaryngol. 2013;270(9):2465-72.

22. Hermelingmeier KE, Weber RK, Hellmich M, Heubach CP, Mosges R. Nasal irrigation as an adjunctive treatment in allergic rhinitis: a systematic review and meta-analysis. Am J Rhinol Allergy. 2012;26(5):e119-25.

23. Pfaar O, Urry Z, Robinson DS, et al. A randomized placebo-controlled trial of rush preseasonal 
depigmented polymerized grass pollen immunotherapy. Allergy. 2012;67(2):272-9.

24. Klimek L, Bachert C, Mosges R, et al. Effectiveness of MP29-02 for the treatment of allergic rhinitis in real-life: results from a noninterventional study. Allergy Asthma Proc. 2015;36(1):40-7.

25. Fendrick AM, Monto AS, Nightengale B, Sarnes M. The economic burden of non-influenza-related viral respiratory tract infection in the United States. Arch Intern Med. 2003;163(4):487-94.

26. Graf P, Juto JE. Sustained use of xylometazoline nasal spray shortens the decongestive response and induces rebound swelling. Rhinology. 1995;33(1):14-7.

27. Graf P. Adverse effects of benzalkonium chloride on the nasal mucosa: allergic rhinitis and rhinitis medicamentosa. Clin Ther. 1999;21(10):1749-55.

28. Watanabe $\mathrm{H}$, Foo TH, Djazaeri B, Duncombe $\mathrm{P}$, Mackay IS, Durham SR. Oxymetazoline nasal spray three times daily for four weeks in normal subjects is not associated with rebound congestion or tachyphylaxis. Rhinology. 2003;41(3):167-74.

29. Yoo JK, Seikaly H, Calhoun KH. Extended use of topical nasal decongestants. Laryngoscope. 1997;107(1):40-3.

30. Eichel A, Bilstein A, Werkhauser N, Mosges R. Meta-analysis of the efficacy of ectoine nasal spray in patients with allergic rhinoconjunctivitis. J Allergy (Cairo). 2014;2014:292545.

31. Eitenmuller A, Piano L, Bohm M, et al. Liposomal nasal spray versus guideline-recommended steroid nasal spray in patients with chronic rhinosinusitis: a comparison of tolerability and quality of life. J Allergy (Cairo). 2014;2014:146280.

32. Sonnemann U, Moller M, Bilstein A. Noninterventional open-label trial investigating the efficacy and safety of ectoine containing nasal spray in comparison with beclomethasone nasal spray in patients with allergic rhinitis. J Allergy (Cairo). 2014;2014:297203.

33. Sonnemann U, Scherner O, Werkhauser N. Treatment of rhinitis sicca anterior with ectoine containing nasal spray. J Allergy (Cairo). 2014;2014:273219.
34. Unfried K, Kroker M, Autengruber A, Gotic M, Sydlik U. The compatible solute ectoine reduces the exacerbating effect of environmental model particles on the immune response of the airways. J Allergy (Cairo). 2014;2014:708458.

35. Werkhauser N, Bilstein A, Sonnemann U. Treatment of allergic rhinitis with ectoine containing nasal spray and eye drops in comparison with azelastine containing nasal spray and eye drops or with cromoglycic acid containing nasal spray. J Allergy (Cairo). 2014;2014:176597.

36. Passali D, Bellussi LM, Gregori D, Lauriello M, Passali FM, Passali GC. Nasal obstruction as a key symptom in allergic rhinitis: efficacy and safety of a medical device in children. Otolaryngol Pol. 2012;66(4):249-53.

37. Passali D, Passali FM, Loglisci M, Cambi J, Bellussi LM. Efficacy and safety of a medical device in reducing nasal obstruction in allergic children. Minerva Pediatr. 2015;67(3):239-43.

38. Castellano F, Mautone G. Decongestant activity of a new formulation of xylometazoline nasal spray: a double-blind, randomized versus placebo and reference drugs controlled, dose-effect study. Drugs Exp Clin Res. 2002;28(1):27-35.

39. Mösges R, Spaeth J, Berger K, Dubois F. Topical treatment of rhinosinusitis with fusafungine nasal spray. A double-blind, placebo-controlled, parallel-group study in 20 patients. Arzneimittelforschung. 2002;52(12):877-83.

40. Eccles R, Winther B, Johnston SL, Robinson P, Trampisch M, Koelsch S. Efficacy and safety of iota-carrageenan nasal spray versus placebo in early treatment of the common cold in adults: the ICICC trial. Respir Res. 2015;16:121.

41. Fokkens WJ, Lund VJ, Mullol J, et al. European position paper on rhinosinusitis and nasal polyps 2012. Rhinol Suppl. 2012(23):3 p preceding table of contents, 1-298.

42. Stuck BA, Bachert C, Federspil P, et al. Rhinosinusitis guidelines-unabridged version: S2 guidelines from the German Society of Otorhinolaryngology, Head and Neck Surgery. HNO. 2012;60(2):141-62. 